doi:10.1017/\$1041610219000747

\section{How are medics approaching people with dementia in Latin America?}

It is estimated that $60 \%$ of all people living with dementia today reside in low and middle-income countries like those in Latin America, and this proportion is expected to increase (World Alzheimer Report 2015). Unfortunately, physicians seem to have a poor knowledge about this condition (Richly et al., 2018), and this may impact their approach to subjects with dementia (Jacinto et al., 2016).
This study was a descriptive and cross-sectional study aimed to investigate physicians' approaches to dementia in Latin America. Participants were medical doctors recruited by a banner at the IntraMed home page (the largest online Spanish-speaking medical community), which invited them to voluntarily access an online questionnaire regarding dementia care. All statistical analyses were conducted using the IBM-SPSS 19.0 package.

The subjects were grouped in three different categories: specialists (neurologists, psychiatrists, and geriatricians), generalists (general practitioners, family physicians, and internal medicine specialists) and others. Only generalists $(n=620)$ and specialists $(\mathrm{n}=432)$ were included in the analysis (Figure 1).

Specialists

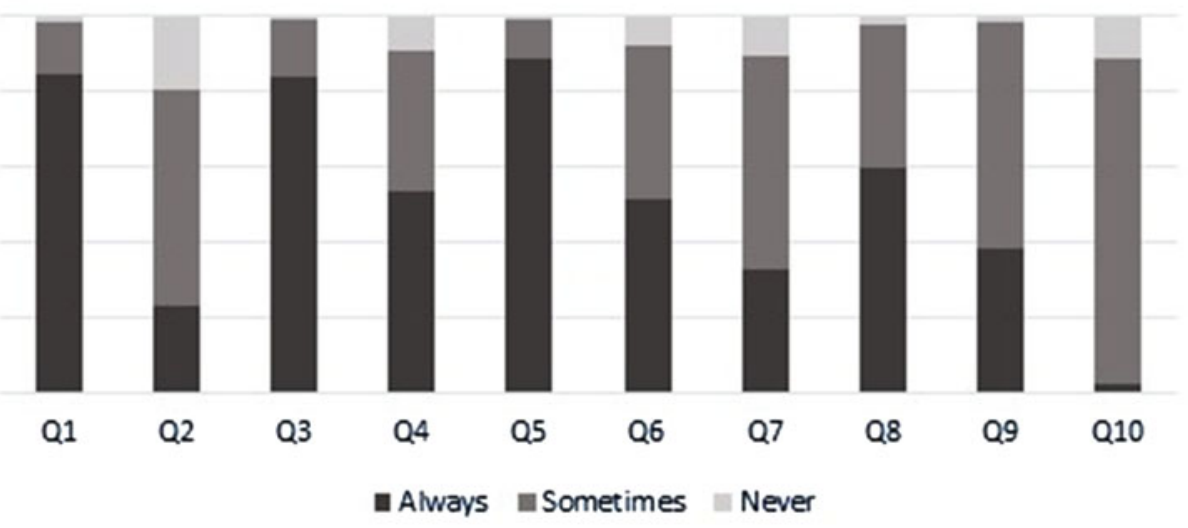

Generalists

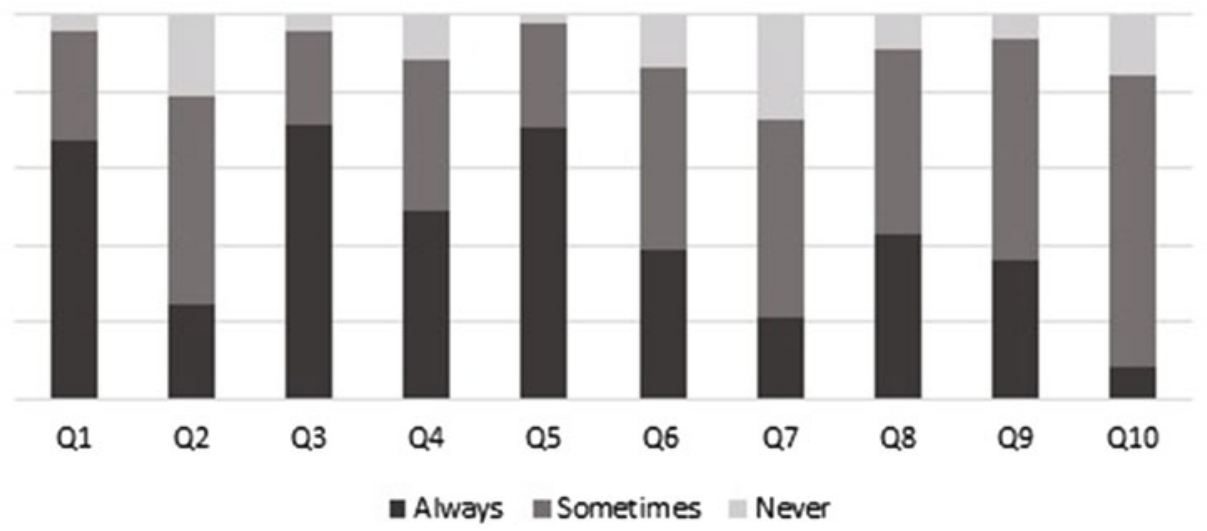

Figure 1. How medics approach subjects with dementia in their practice. 
No differences were found in age or sex within both groups.

Specialist were more likely to let the family participate in the interview $(\operatorname{sig}=0.001)$ and share with them the diagnosis than generalists $(\operatorname{sig}=0.001)$. However, neither of them frequently disclosed the diagnosis with the subjects $(\operatorname{sig}=0.941)$ or discussed with them about advance care directives on a regular basis $(\operatorname{sig}=0.110)$.

Also, generalists were less likely to provide the family with tips on how to manage everyday issues related to dementia $(\mathrm{sig}=0.001)$ or give guidance regarding social security strategies than specialists $(\operatorname{sig}=0.001)$. Even though specialists were more likely to consider themselves as the patient's "case manager" $(\operatorname{sig}=0.001)$ or discuss long-term care plans $(\mathrm{sig}=0.001)$ than generalists, only one-third did so. There were no relevant differences between the two groups regarding the suggestions about a formal caregiver $(\operatorname{sig}=0.104)$ or institutionalization $(\operatorname{sig}=0.759)$.

The findings of this study are a warning sign about the relevance of a competence-based education program, rather than focusing only in disease knowledge. Latin American physicians are lacking not only information about dementia, but also the skills and commitment to help patients and families to deal with this life-changing condition. It is likely that this could be better tackled by public programs with a community perspective, and therefore, government involvement would be necessary (Manes et al., 2016).

\section{Conflict of Interest}

All the authors declare no conflict of interest.

\section{References}

Jacinto, A. F., et al. (2016). Knowledge and attitudes towards dementia in a sample of medical residents from a university-hospital in São Paulo, Brazil. Dementia and Neuropsychologia, 10, 37-41.

Manes, F. (2016). The huge burden of dementia in Latin America. The Lancet Neurology, 15, 29.

Richly, P., et al. (2018). Are medical doctors in Latin America prepared to deal with the dementia epidemic?. International Psychogeriatrics, 1-2. doi: 10.1017/ S1041610218001825

World Alzheimer Report. 2015. The Global Impact of Dementia: an analysis of prevalence, incidence, cost and trends. Available at https://www.alz.co.uk/research/worldreport-2015

Pablo Richly, ${ }^{1}$ Santiago Oneill, ${ }^{2}$ Daniel Flichtentrei ${ }^{3}$ and Pablo Lopez ${ }^{4}$

${ }^{1}$ Instituto De Neurologia Cognitiva, Buenos Aires, Argentina

${ }^{2}$ Fundacion Favaloro, Buenos Aires, Argentina

${ }^{3}$ IntraMed, Olivos, Buenos Aires, Argentina

${ }^{4}$ Instituto De Neurologia Cognitiva, Buenos Aires, Argentina

Correspondence should be addressed to: Pablo Richly, Instituto De Neurologia Cognitiva, Pacheco de Melo, 1854/60, Buenos Aires C1126AAB, Argentina. Phone/Fax: +54911 4812-0010. Email: richlypablo@gmail.com. 